\title{
Laboratory Evaluation of Newly Formulated Thermoplastic Resin Complete Denture Base Materials
}

\author{
El-Khodary N. M. ${ }^{1}$, El-Shabrawy S. M. ${ }^{2}$, El-Naihoum W. A. ${ }^{3}$ \\ ${ }^{1}$ Professor of Prosthodontics, Alexandria University Faculty of Dentistry, Alexandria, Egypt \\ ${ }^{2}$ Professor of Biomaterial, Alexandria University Faculty of Dentistry, Alexandria, Egypt \\ ${ }^{3}$ BDS, Faculty of Dentistry, Benghazi University, MS, Alexandria University, Egypt
}

\begin{abstract}
Aim of the work: To investigate the physic-mechanical properties of newly formulated thermoplastic denture base material. Materials and Methods: Two parallel groups according to the denture base material used Group (A) conventional heat cure acrylic resin $i$.e. control group, Group (B)Vertex thermosens i.e. test group, 35 specimens each (14 impact, 14 flexural and 7warpage)will be examined in this study. Each group will be divided into 2 subgroups: (I) No Thermocycling and (II) Thermocycling then subjected to 3 different tests, Impact strength, flexural strength and warpage. Results and Conclusions: 1.The vertex thermosens denture base material exhibited significantly higher impact and flexural strength as compared with conventional PMMA.2.There was significant increase in impact strength of vertex thermosens and non statistically significant of flexural strength of both groups after thermocycling.3. Warpage of vertex thermosens was statistically significant higher than conventional PMMA.4.There was a significant increase of warpage after thermocycling for both groups.
\end{abstract}

Keywords: Denture base materials, polyamide, thermosens, impact, flexural, warpage, thermocycling.

\section{Introduction}

Poly methyl methacrylate (PMMA) resin has been widely used as a denture base material due to its desirable properties of excellent esthetics, ability to repair, low water sorption and solubility, adequate strength, low toxicity, and simple processing technique.[1, 2]

Poly methyl methacrylate denture base has dominated the market for more than 50 years.[3]

Conversely some disadvantages have also been described, such as polymerization shrinkage, weak flexural, lower impact strength, low fatigue resistance and in cases where patient is allergic to monomer.[4-6]

These often lead to denture failure during chewing or when fall out of the patient's hand. Continuous efforts to increase material strength to decrease the risk of denture fractures can be listed as:

(1) reinforcement of denture materials by adding filling materials, [7] (2) changing the chemistry of the denture base polymer by copolymerizationand cross-linking of resin materials, (3) incorporation oftechniques new to the dental field; and (4) manufacturing new materials with increased resistance to fracture.[8, 9] One technique that improves the physical properties of dentures is injection molding technique to allow directional control of the polymerization process through the flask design, and involves a constant flow of new material from the sprue, thereby compensating for polymerization shrinkage.[10, 11]

Thermoplastic materials, such as polyamides (nylon plastics) were developed: acetal, polycarbonate, acrylic and nylon (resin).Nylon is a generic name used for certain types of thermoplasticpolymers belonging to the class known as polyamides.[12]A new material called ThermoSens is superior to standard polyamide materials. The flexibility of this material can be controlled, and its shrinkage is extremely low. Owing to its composition, a homogenous color can be achieved, making this material suitable for the preparation of full dentures.[13]

In present study, the most important physico-mechanical properties were made to compare between the polyamide based denture base material (Vertex ${ }^{\mathrm{TM}}$ ThermoSens

Vertex-Dental B.V. The Netherlands) as and conventional poly methyl methacrylate resin PMMA (Acrostone, Egypt) and test the hypothesis that those properties could be affected by thermocycling.

\section{Materials and Methods}

The materials that used in this study were summarized in table 1.

Table 1: Materials used in the study

\begin{tabular}{|c|c|c|c|}
\hline & Manufacture & Material & $\begin{array}{c}\text { Manufacturing } \\
\text { method }\end{array}$ \\
\hline Acrostone & $\begin{array}{c}\text { Acrostone, } \\
\text { Egypt. }\end{array}$ & PMMA & $\begin{array}{c}\text { Compression } \\
\text { methodtechnique } \\
\text { using conventional } \\
\text { curing unit (long } \\
\text { curing cycle) } 70^{\circ} \mathrm{C} \text { for } \\
7-9 \text { hours then } \\
100^{\circ} \text { Cfor } 30 \text { minutes. }\end{array}$ \\
\hline Thermosens & $\begin{array}{l}\text { Vertex-Dental } \\
\text { B.V. } 3705 \text { HJ } \\
\text { Zeist The } \\
\text { Netherlands. }\end{array}$ & Polyamide & $\begin{array}{l}\text { Injection method } \\
\text { technique using a } \\
\text { pressure of } 6.5 \mathrm{bar} \\
\text { with preheating of } \\
\text { the cylinder of the } \\
\text { thermoject machine } \\
\text { to } 290^{\circ} \mathrm{C} \text { for } 18 \mathrm{~min} \text {. }\end{array}$ \\
\hline
\end{tabular}

The following laboratory tests for evaluation of physicomechanical properties were done( Impact strength test (IS), Flexural strength test (FS)and Warpage). 


\section{International Journal of Science and Research (IJSR) \\ ISSN (Online): 2319-7064 \\ Index Copernicus Value (2013): 6.14 | Impact Factor (2014): 5.611}

A total of(70)Specimens that were prepared according to the international standers specifications for each test. The specimens were divided into two groups as following:

Group (A) i.e(control group): Specimens of conventional heat cure acrylic resin denture base material (PMMA).

Group (B)i.e (study group): Specimens of thermoplastic resin material (Vertex ${ }^{\text {TM }}$ Thermosens).

Each group was divided into 2 subgroups:

Subgroup I: Specimens were stored in the incubator at 37 ${ }^{0} \mathrm{C}$ for 24 hours (called thermocycle zero or no thermocycle). Subgroup II:Specimens for each test were thermocycled to examine the effects of temperature variations .

\section{Specimens Preparation}

1. For impact strength test: Metallic mold having the dimensionsof impact strength test specimensaccording to the method described in the ISOstandard (ISO 179-1;2010) bar shapedof $75 \mathrm{~mm}$ length, $10 \mathrm{~mm}$ width, $10 \mathrm{~mm}$ thickness with notchof $2 \mathrm{~mm}$ depth at the mid span was constructed.

Base platewax softened and poured into the mold . After hardeningthe wax was removed. A totalof 28 wax specimens wereprepared according to the type of denture base materialsFig.1used forconstruction of specimens the 28 test specimenswere divided equally into two groups(A\&B) of 14 specimens each. Subgroup I:7 specimens were stored in distilled water at $37^{\circ} \mathrm{C}$ in the incubator. Time (time taken by the specimens to be transferred from one bath to another) of 5 seconds.Subgroup II:7 specimens were thermocycling using a thermocycling machine for 500 cycles between $55^{\circ} \mathrm{C}$ and $5^{\circ} \mathrm{C}$ with a dwell time (time taken by the specimens in each bath) of 60 seconds and transfer

The specimens was accurately mounted in the vice of the pendulum testing machine (charpy type impact tester) (Mfd for Dayton Electric Co. Chicago 60648 USA(CEDM-4).

The specimens was struck at the mid-span by the pendulum as it releasing out of position (The force was applied to the specimen from the unnotched side).

The charpy impact strength of the specimen was calculated in $\mathrm{KJ} / \mathrm{mm}^{2}$ as given by the following equation[14, 15]:

$$
\text { Impact strength }=\frac{\mathrm{B}}{\mathrm{bd}} \times 10^{3}
$$

Where:

$\mathrm{E}$ : is the impact absorbed energy in joules.

$\mathrm{b}$ : is the width in millimeters of the test specimens.

$\mathrm{d}$ : is the thickness in millimeters of the test specimens.

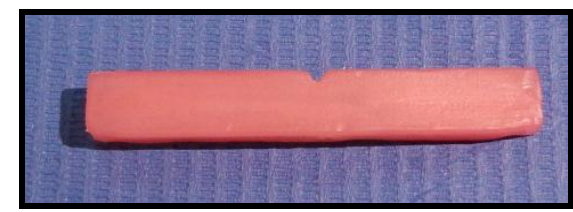

Figure 1: Impact test specimen

2. For flexural strength test: metallic mold having the dimensions of flexural strength test specimens according to the American Dental Association Specification No.12 for denture base polymer (65 mm length, $10 \mathrm{~mm}$ width and 2.5 mm thickness) was constructed .Base plate wax softened and poured intothe mold .After hardening the wax was removed.A total of 28 wax specimens were prepared Fig. (2).

According to the type of denture base material used forconstruction of specimens the 28 test specimens were divided equally into two groups (A\&B) of 14 specimens each, processing was done according to the manufacture instructions In order to test the effect of thermocycling on the flexural strength of the specimens under testing, the specimens of each group (A\&B) were divided into equal subgroups of seven specimens each. Subgroup I:7 specimens were stored in distilled water at $37{ }^{\circ} \mathrm{C}$ in the incubator. Subgroup II:7 specimens were thermocycling using a thermocycling machine.Individual specimens were placed on supports of the universal testing machine (Comten Industries, Inc.St. petersburg, Florida, USA, ModelNo.942D10-20). While placing the specimen on the testing device, care was taken that the central loading plunger was touching the midline of the sample. The force in Newton was applied perpendicular to the center of specimen strips and the specimen was gradually loaded at a crosshead speed of $0.5 \mathrm{~mm} \mathrm{~min}^{-1}$. The maximumfracture load was measured for Acroston (group A). Thermosens specimens(group B) did not fracture, so the load was applied till maximum capacity of the three-point testing device will be recorded. The flexural strength will be calculated according to the following equation[6, 16]:

$$
\text { Flexural strength }(\mathrm{S})=\frac{3 P L}{2 b d^{2}}(M p a)
$$

Where:

$\mathrm{P}=$ load at fracture (or., load at maximum deflection).

$\mathrm{L}=$ distance between the two supporting point. $(50 \mathrm{~mm})$.

$\mathrm{b}=$ width of the test specimens. $(10 \mathrm{~mm})$

$\mathrm{d}=$ thickness of specimen.(2.5 mm).

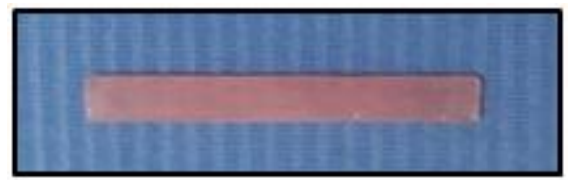

Figure 2: Flexural test specimen.

3.For warpage test: A sectional maxillary metal cast which nearly represents the dimensions of the edentulous ridge was constructed . Five fine parallel lines were inscribed on the posterior aspect of the metal master cast to be used as a reference measuring locations .A rubber base mold was prepared for this metallic cast.

1) A mix of pure stone with a constant water/powder ratio 3:1 was maintained for all casts. Then the mix poured in the rubber base mold which was placed on a vibrator to remove any air bubbles present in the mix. After hardening, the stone casts were removed.

2) Following the previous steps identical standardized sectional stone casts were prepared for all the experiment.

3) A uniform baseplate wax was adapted upon each a sectional stone cast with a $2.0 \mathrm{~mm}$ thickness and sealed at the peripheries. 


\section{International Journal of Science and Research (IJSR) \\ ISSN (Online): 2319-7064 \\ Index Copernicus Value (2013): 6.14 | Impact Factor (2014): 5.611}

4) Flasking, wax elimination (dewaxing), packing, curing and deflasking was performed carefully to avoid damage of casts. Polishing was usually carried out under running water to avoid rise in temperature and subsequent warpage by using motor lathe.

The posterior peripheral seal area displays the greatest discrepancy of adaptation after processing due to shrinkage of denture base material and strain release induced by thermal change[17].

These discrepancy or space observed between the denture bases and their casts.The vertical distance between the end of the finished plate and the originalstandardized casts were measured at "five locations"at the posterior palatal border. Location (C) representnearly the center of the palate. Location (R) and (L)represent nearly the crest of the ridge.location (A) and(B) represent nearly the intermediatepointsbetween the center of the palate (C) and the crestof the ridge (R, L)[18]Fig.(3).

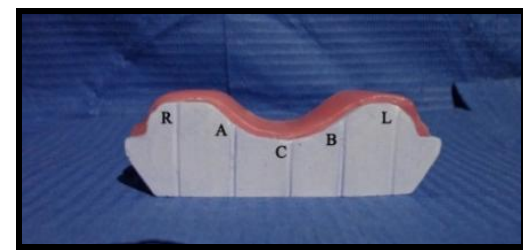

Figure 3: Warpage test specimen.

The measurement werecarried out by using Stereomicroscope with camera attached was used to Stereomicroscope(SZII, Olympus optical co.ltd.2-43, 2Hatagaya, Shibuy-Ku, Tokyo, Japan.)

The measurement of warpage (for each specimen in different groups) were carried out at the following stages:

1. Immediately after processing, deflasking and finishing of plates.

2. After stored in distilled water at $37^{\circ} \mathrm{C}$ in the incubator for 24 hours.

3. After thermocycling the specimens for 500 cycles between $55^{\circ} \mathrm{C}$ and $5^{\circ} \mathrm{C}[17]$.

The captured photographs were loaded on an image-J software that was used to measure the distance in micron between the predetermined location on the cast and the base plate in vertical direction.

\section{Results}

Data were fed to the computer and analyzed using IBM SPSS software package version 20.0. Quantitative data were described using range (minimum and maximum), mean, standard deviation and median. Significance of the obtained results was judged at the $5 \%$ level.

\section{Impact Strength Test}

During testing, all the specimens of two groups fractured immediatelyafter the first strike producing a clean fracture surface, the fracture line started from the base of the $\mathrm{v}$ shape notch and extended downward.All the fractured specimens could be reassembled. Table(2) \& figure(4) compare the mean values of impact strength of specimen for both groups at different conditions, and represent the effect of thermocycle on them.

- Man whitney test was used for comparing between the two studied group at different condition.

- In general the impact strength of thermosens was higher than conventional PMMA.

- Wilcoxon signed ranks test was used for comparing between Zero and after thermocycle for each group where $(\mathrm{Z} 2=1.572) \quad(\mathrm{p}=0.116)$ for group $\mathrm{A} \& \quad(\mathrm{Z} 2=2.028)$ $(\mathrm{p}=0.043)$ for group $\mathrm{B}$.

- At zero thermocycle the results were analyzed and compared between the two studied groups which revealed a significant increase in impact strength for group II $(\mathrm{Z} 1=2.310)(\mathrm{P}=0.021)$.

- After thermocycling, there was significant difference in the impact strength with $(\mathrm{Z} 1=2.719)(\mathrm{P}=0.007)$ of vertex thermosens.

Table 2: Comparison between the mean values of impact strength for the two studied groups and subgroups in

\begin{tabular}{|c|c|c|c|c|}
\hline $\begin{array}{c}\text { Impact Strength } \\
\text { values }\end{array}$ & \begin{tabular}{|c|} 
Group A \\
Conventional \\
PMMA \\
$(n=14)$ \\
\end{tabular} & $\begin{array}{c}\text { Group B } \\
\text { Vertex } \\
\text { thermosens } \\
(n=14) \\
\end{array}$ & $Z_{1}$ & $p$ \\
\hline \multicolumn{5}{|l|}{\begin{tabular}{|l|} 
Zero thermocycle \\
\end{tabular}} \\
\hline Min. - Max. & $12.50-16.25$ & $12.50-25.50$ & \multirow{3}{*}{$2.310^{*}$} & \multirow{3}{*}{$0.021^{*}$} \\
\hline Mean \pm SD. & $15.02 \pm 1.38$ & $20.80 \pm 4.04$ & & \\
\hline Median & 15.60 & 21.30 & & \\
\hline \multicolumn{5}{|l|}{ After thermocycle } \\
\hline Min. - Max. & $15.0-35.0$ & $16.50-173.7$ & \multirow{3}{*}{$2.719^{*}$} & \multirow{3}{*}{$0.007^{*}$} \\
\hline Mean \pm SD. & $18.73 \pm 7.28$ & $87.17 \pm 70.46$ & & \\
\hline Median & 15.60 & 52.50 & & \\
\hline $\mathrm{Z}_{2}(\mathrm{p})$ & $1.572(0.116)$ & $2.028^{*}\left(0.043^{*}\right)$ & & \\
\hline \% of change & $\uparrow 24.70$ & $\uparrow 119.09$ & & \\
\hline
\end{tabular}

$\mathrm{Z}_{1}$ : Z value for Mann Whitney test for comparing between the two studied groups

$\mathrm{Z}_{2}$ : $\mathrm{Z}$ value for Wilcoxon signed ranks test for comparing between Zero and after thermocycle for each group.

*: Statistically significant at $\mathrm{p} \leq 0.05$.

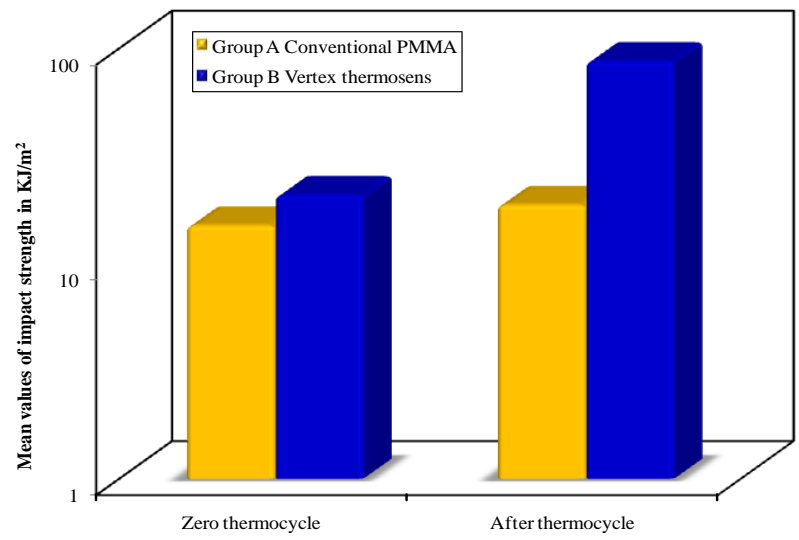

Figure 4: Comparison between the two studied groups according to impact Strength values in $\mathrm{KJ} / \mathrm{m}^{2}$ before and after thermocycling. 


\section{International Journal of Science and Research (IJSR) \\ ISSN (Online): 2319-7064 \\ Index Copernicus Value (2013): 6.14 | Impact Factor (2014): 5.611}

Flexural Strength Test:

During testing, the acrylic spesimens for group A showed gradual bending then finally broken in clean cut.In all the specimens the fracture line was sharp and located nearly at the center of the specimens where the load applied.All fractured specimens could be reassebling and the line of fracture was not clearly seen.In group $\mathbf{B}$ the specimens showed gradually bending till the maximum deflection capacity of the material without fracture.

- Table(3) and figure(5) show the mean flexural strength values for both studied groups (i.e. group A and group B )at both condition (i.e. zero thermocycling and after thermocycling).

- When compare the two groups we found that the thermosens denture base material has a higher flexural strength than conventional denture base material in both (zero and after thermocycling) with significantly different $\left(\mathbf{t}_{\mathbf{1}}=7.396\right)$ $(\mathrm{p}=<0.001)$ at zero thermocycle and $\left(\mathrm{t}_{\mathbf{1}}=3.476\right)(\mathrm{P}=0.005)$ after thermocycling.

Table 3: Comparison between the two studied groups according to Flexural Strength in Mpa at zero thermocycle and after thermocycle

\begin{tabular}{|c|c|c|c|c|}
\hline $\begin{array}{c}\text { Flexural Strength } \\
\text { test }\end{array}$ & $\begin{array}{c}\text { Group A } \\
\text { Conventional } \\
\text { PMMA } \\
(n=14) \\
\end{array}$ & $\begin{array}{l}\text { Group B } \\
\text { Vertex } \\
\text { thermosens } \\
(n=14)\end{array}$ & $t_{1}$ & $P$ \\
\hline \multicolumn{5}{|l|}{ Zero thermocycle } \\
\hline Min. - Max. & $85.01-148.9$ & $181.9-232.1$ & \multirow{3}{*}{$7.396^{*}$} & \multirow{3}{*}{$<0.001^{*}$} \\
\hline Mean \pm SD. & $119.1 \pm 29.12$ & $212.6 \pm 16.53$ & & \\
\hline Median & 120.9 & 216.0 & & \\
\hline \multicolumn{5}{|l|}{ After thermocycle } \\
\hline Min. - Max. & $118.7-187.4$ & $175.6-290.4$ & \multirow{3}{*}{$3.476^{*}$} & \multirow{3}{*}{$0.005^{*}$} \\
\hline Mean \pm SD. & $141.4 \pm 26.06$ & $203.2 \pm 39.19$ & & \\
\hline Median & 127.9 & 191.9 & & \\
\hline$t_{2}(p)$ & $1.369(0.220)$ & $0.630(0.552)$ & & \\
\hline$\%$ of change & $\uparrow 18.72$ & $\downarrow 4.42$ & & \\
\hline
\end{tabular}

$\mathrm{t}_{1}$ : Student t-test for comparing between the two studied groups $t_{2}$ : Paired t-test for comparing between Zero and after thermocycle in each group.

*: Statistically significant at $\mathrm{p} \leq 0.05$

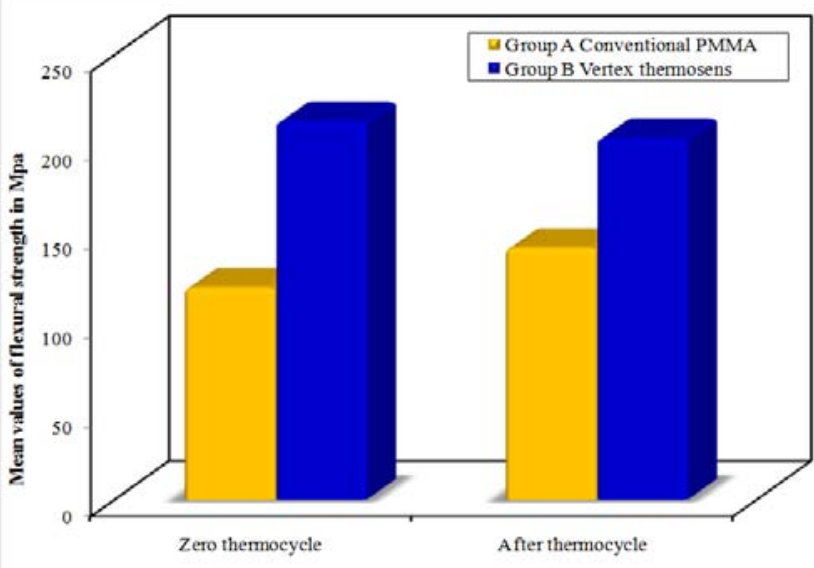

Figure 5: Comparison between the two studied groups according to Flexural Strength values.

\section{Warpage Test:}

Warpage appears in the form of seperation of the plate from the stone cast.The mean value of space between the plates and their stone casts at different location measurment for two groups in all observational stages are presented in table (4).

The analysis of data showed that the amount of space between the plates and their stone casts in both groups was greatest at the center of plates and gradually decreased toward the crest of the ridge fig.(6a, b). when compared the two study groups (A and $\mathbf{B}$ ) by using Student t-tes t\& ANOVA with repeated measures in table (5) figure (7) at each stages the $\mathrm{P}$ value was statictically different at each different level $(\mathrm{p}<0.001)$.

Table 4: The mean values \pm SD of spaces in micron at each location for both groups.

\begin{tabular}{|c|c|c|c|c|c|c|}
\hline \multirow{2}{*}{$\begin{array}{c}\text { Measurements } \\
\text { points }\end{array}$} & \multicolumn{3}{|c|}{ Group A Conventional PMMA } & \multicolumn{3}{c|}{ Group B Vertex thermosens } \\
\cline { 2 - 7 } & Immediately & Zero thermocycle & After thermocycle & Immediately & Zero thermocycle & After thermocycle \\
\hline R (Mean \pm SD) & $153.8 \pm 75.7$ & $194.8 \pm 50.1$ & $207.6 \pm 69.7$ & $301.8 \pm 117.0$ & $319.6 \pm 190.7$ & $452.0 \pm 156.5$ \\
\hline A (Mean \pm SD) & $193.5 \pm 62.2$ & $258.7 \pm 77.7$ & $300.6 \pm 49.1$ & $356.9 \pm 193.1$ & $347.6 \pm 137.0$ & $452.6 \pm 173.9$ \\
\hline C(Mean \pm SD) & $247.4 \pm 100.3$ & $275.9 \pm 69.1$ & $320.9 \pm 94.1$ & $406.7 \pm 97.0$ & $486.5 \pm 185.8$ & $597.9 \pm 182.3$ \\
\hline B(Mean \pm SD) & $217.8 \pm 86.2$ & $233.8 \pm 62.1$ & $283.5 \pm 83.4$ & $390.9 \pm 178.3$ & $460.6 \pm 130.0$ & $569.4 \pm 108.7$ \\
\hline L(Mean \pm SD) & $192.2 \pm 53.6$ & $228.1 \pm 83.6$ & $280.3 \pm 83.9$ & $305.2 \pm 107.6$ & $418.8 \pm 107.7$ & $439.2 \pm 108.2$ \\
\hline
\end{tabular}

Data was expressed by using mean \pm SD. 


\section{International Journal of Science and Research (IJSR) \\ ISSN (Online): 2319-7064}

Index Copernicus Value (2013): 6.14 | Impact Factor (2014): 5.611

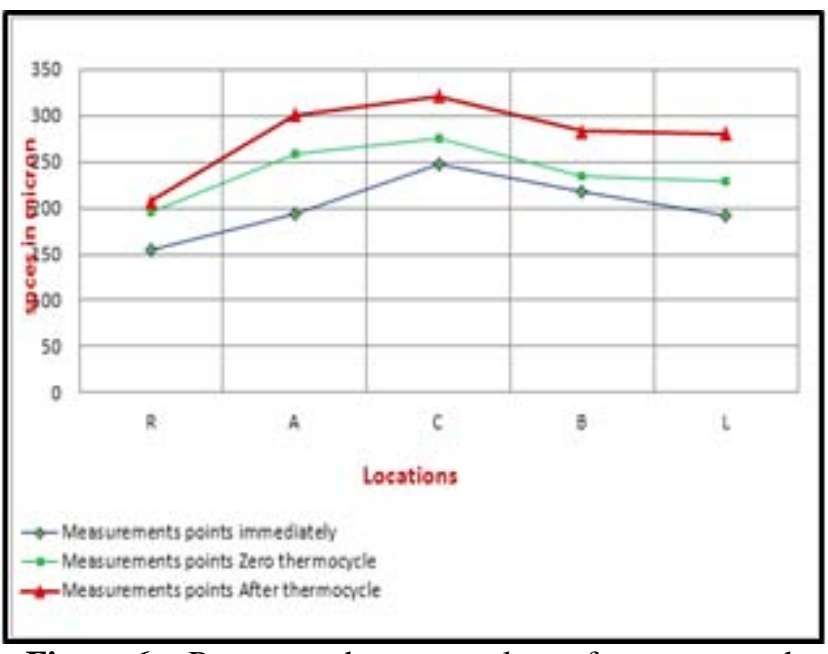

Figure 6a: Represent the mean values of spaces at each measurement location in three different stages for group A.

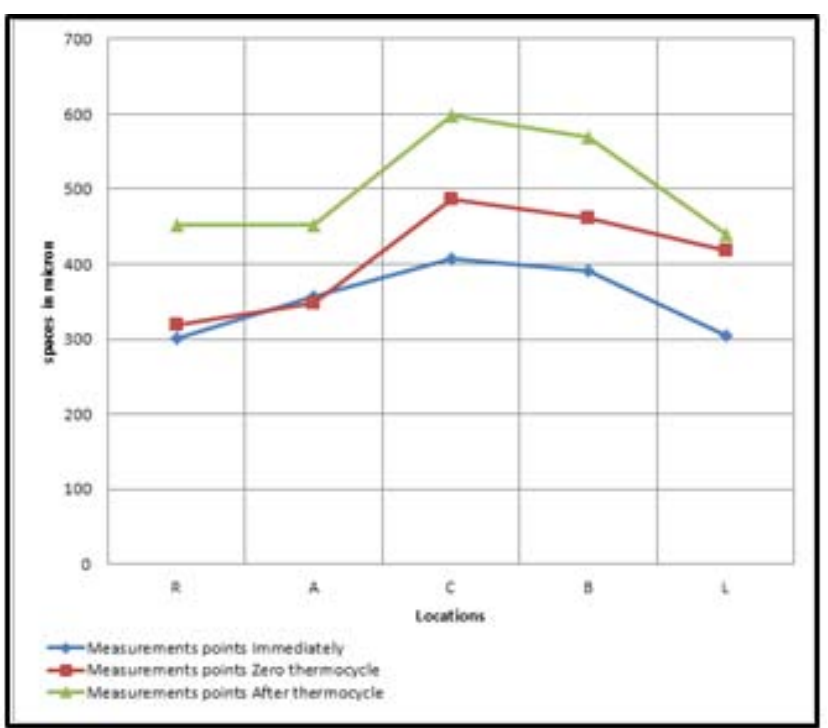

Figure 6b: Represent the mean values of spaces at each measurement location in three different stages for group B.

Table 5: Comparison between the mean values of warpage in micron for the two studied groups before and after thermocycle

\begin{tabular}{|c|c|c|c|c|c|}
\hline Warpage & Immediately & Zero thermocycle & After thermocycle & $\mathbf{F}$ & $\mathbf{p}$ \\
\hline Group A Conventional PMM & & & & & \\
\hline Min. - Max. & $75.30-409.6$ & $108.6-385.9$ & $115.0-483.5$ & \multirow{3}{*}{$8.725^{*}$} & \multirow{3}{*}{$<0.001^{*}$} \\
\hline Mean \pm SD. & $201.0 \pm 79.23$ & $238.3 \pm 71.11$ & $264.4 \pm 83.7$ & & \\
\hline Median & 185.7 & 235.0 & 257.4 & & \\
\hline Sig. bet. periods & \multicolumn{3}{|c|}{$\mathrm{p}_{1}=0.009^{*}, \mathrm{p}_{2}=0.001^{*}, \mathrm{p}_{3}=0.068$} & & \\
\hline \% of change & & $\uparrow 18.56$ & $\uparrow 31.54$ & & \\
\hline Group B Vertex thermosen & & & & & \\
\hline Min. - Max. & $97.92-691.93$ & $84.20-875.0$ & $215.4-884.0$ & \multirow{3}{*}{$19.158^{*}$} & \multirow{3}{*}{$<0.001^{*}$} \\
\hline Mean \pm SD. & $352.3 \pm 142.2$ & $406.6 \pm 158.3$ & $502.2 \pm 156.0$ & & \\
\hline Median & 313.6 & 378.6 & 481.9 & & \\
\hline Sig. bet. periods & \multicolumn{3}{|c|}{$\mathrm{p}_{1}=0.065, \mathrm{p}_{2}<0.001^{*}, \mathrm{p}_{3}<0.001^{*}$} & & \\
\hline$\%$ of change & & $\uparrow 15.41$ & $\uparrow 42.55$ & & \\
\hline $\mathbf{t}$ & $5.501^{*}$ & $5.740^{*}$ & $7.948^{*}$ & & \\
\hline $\mathbf{p}$ & $<0.001^{*}$ & $<0.001^{*}$ & $<0.001^{*}$ & & \\
\hline
\end{tabular}

t: Student t-test

F: $F$ test (ANOVA) with repeated measures,

Sig. bet. periods was done using Post Hoc Test (LSD) for ANOVA with repeated measures

p1: p value for comparing between Immediately and Zero thermocycle

p2: p value for comparing between Immediately and After thermocyclep3: p value for comparing between Zero thermocycle and After thermocycle

*: Statistically significant at $\mathrm{p} \leq 0.05$

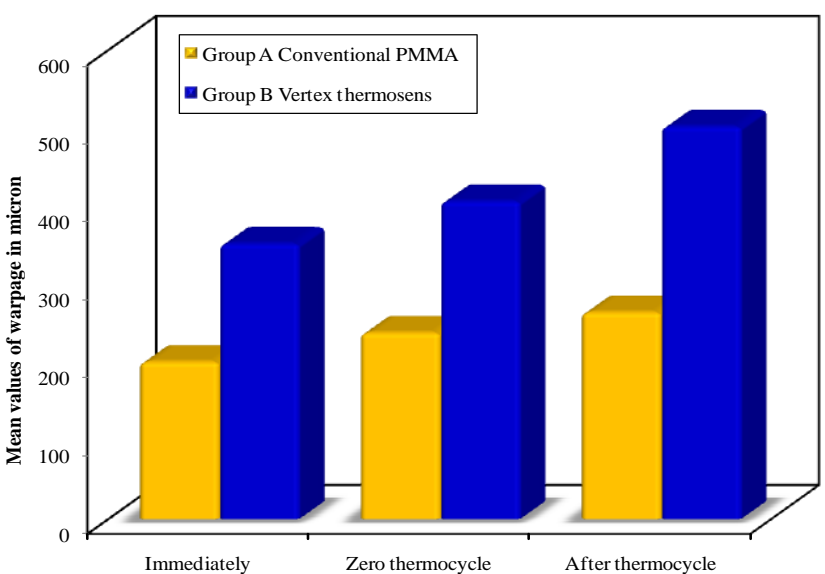

Figure 7: Comparison between the two studied groups at different stages of measurement.

\section{Discussion}

\section{Impact Strength Test}

Impact strength is an important property for denture base materials which have tendency to fracture if accidentally dropped on to a hard surface.[14] There fore the impact strength test was conducted in this study as one of the tests for evaluation of mechanical properties of denture base.

As regards the this study, when compare the mean values of impact strength of specimen for both groups at different conditions, and represent the effect of thermocycle on them, we founded that Vertex thermosens showed significantly higher impact strength than conventional PMMA in both situation.This is may be due to, polyamide structure is based primarily on aliphatic chains.[19] The backbone of Polyamide is regular and symmetrical, so forms very good resistance to shock and repeating stress.[7] 


\section{International Journal of Science and Research (IJSR) \\ ISSN (Online): 2319-7064 \\ Index Copernicus Value (2013): 6.14 | Impact Factor (2014): 5.611}

In addition, Porosities of PMMA more than that of Polyamide denture base material, this comes from presence of residual monomer and its evaporation leads to formation of these porosities, also the compression packing technique of conventional PMMA leads to more porosities than injection molding processing of polyamide.[20] Polyamide contains flexible agents in its composition, so it absorbs more energy to fracture.[21]Generally, our finding are supported byAmeer (2012)[3]and Takahashi et al (2012).[22]

\section{Flexural Strength Test}

Flexural strength is an important parameters that can reflect the ability of a denture base material to withstand functional masticatory forces.The three-point flexural strength test is useful in comparing denture base materials because it simulates the type of stress that is applied to the denture during mastication.[23, 24]

Moreover, the flexural strength test is a combination of tensile and compressive strength tests and includes some of the elements of proportional limit and elastic modulus measurements.[25]When comparing (group A\& group B), the vertex thermosens flexural strength was significantly higher than that conventional PMMA in both condition (Zero thermocycle\& after thermocycling).

This may be due to different in the composition of denture base material and polymerization technique, Our finding are supported by Takahashi et al (2012)[22]and disagree with Yunus et al (2005)[23] and Ammer (2012)[3]they reported that flexural strength of polyamide was lower than conventional PMMA.

\section{Warpage Test}

Warpage appears in the form of seperation of the plate from the stone cast and was selected for testing the specimens since an accurate fit is relatively important because the distance between the base and supporting tissue is one of the principal factors in retention and control of the amount of forces necessary to dislodge the dentures.[26]

The amount of warpage for both groups was measured at the posterior palatal area of sectional plates placed on their stone casts at five predetermined references locations in different stages ;because it can be easily measured and greater degree of dimensional changes were observed in this region in previous study.[27]

Since it is more susceptible to strain release because it is flatter and less restrictive than anterior region due to its anatomy . The results of this study showed that the greatest dimensional change between the plates and stone cast occurred in the median region of the palate (location c) and gradually decrease toward crest of the ridge.The explanation is that the processing shrinkage which occurred in the upper denture tends to draw the flanges inward on the lateral aspects of the tuberosities and as a result the denture was raised from the palate.

When comparing between two groups and sub groups, there were significant difference between conventional PMMA \& vertex thermsens at all different stages, the amount of warpage in group $\mathrm{B}$ was higher than group $\mathrm{A}$. The dimensional characteristics of processed denture bases are affected by many factors, such as the type of acrylic, type of investment material, method of resin introduction and temperature used to activate the polymerization process, seperating medium used and number of sprues used.[28]

Our finding is supported by Parvizi et al (2004)[28] and Ameer(2012).[17]

\section{Conclusions}

Within limitations of this in vitro study, the following conclusions were drawn:

1) The vertex thermosens denture base material exhibited significantly higher impact and flexural strength as compared with conventional PMMA.

2) There was significant increase in impact strength of vertex thermosens and non statistically significant of flexural strength of both groups after thermocycling.

3) Warpage of vertex thermosens was statistically significat higher than conventional PMMA.

4) There was a significant incease of warpage after thermocycling for both groups.

\section{References}

[1] Vojdani M, Khaledi A. Transverse strength of reinforced denture base resin with metal wire and Eglass fibers. Journal of Dentistry of Tehran University of Medical Sciences. 2006;3(4):159-66.

[2] Abuzar MA, Bellur S, Duong N, Kim BB, Lu P, Palfreyman N, et al. Evaluating surface roughness of a polyamide denture base material in comparison with poly (methyl methacrylate). Journal of oral science. 2010;52(4):577-81.

[3] Al-Ameer SS. Effect of thermocycling on some mechanical properties of polyamide hypoallergenic denture base material (comparative study). Scientific Journal Published by the College of DentistryUniversity of Baghdad.2012;24(2):25-30.

[4] Athar Z, Juszczyk A, Radford D, Clark R. Effect of curing cycles on the mechanical properties of heat cured acrylic resins. The European journal of prosthodontics and restorative dentistry. 2009;17(2):58-60.

[5] Ali IL, Yunus N, Abu-Hassan MI. Hardness, flexural strength, and flexural modulus comparisons of three differently cured denture base systems. Journal of Prosthodontics. 2008;17(7):545-9.

[6] Kohli S, Bhatia S. Flexural properties of polyamide versus injection-molded polymethylmethacrylate denture base materials. European Journal of Prosthodontics. 2013;1(3):56.

[7] Doğan OM, Bolayır G, Keskin S, Doğan A, Bek B. The evaluation of some flexural properties of a denture base resin reinforced with various aesthetic fibers. Journal of Materials Science: Materials in Medicine. 2008;19(6):2343-9.

[8] Foo H, Lindquist TJ, Aquilino SA, Schneider RL, Williamson DL, Boyer DB. Effect of polyaramid fiber reinforcement on the strength of 3 denture base polymethyl methacrylate resins. Journal of Prosthodontics. 2001;10(3):148-53.

\section{Volume 5 Issue 3, March 2016}




\section{International Journal of Science and Research (IJSR) \\ ISSN (Online): 2319-7064 \\ Index Copernicus Value (2013): 6.14 | Impact Factor (2014): 5.611}

[9] Ucar Y, Akova T, Aysan I. Mechanical properties of polyamide versus different PMMA denture base materials. Journal of Prosthodontics. 2012;21(3):173-6.

[10] Ganzarolli SM, Nunes de Mello JA, Shinkai RS, Del Bel Cury AA. Internal adaptation and some physical properties of methacrylate-based denture base resins polymerized by different techniques. Journal of Biomedical Materials Research Part B: Applied Biomaterials. 2007;82(1):169-73.

[11] Kieć-Świerczyńska M, Kręcisz B. Allergic contact dermatitis in a dental nurse induced by methacrylates. Int J Occup Med Environ Health. 2003;16(1):73-4.

[12] Kohli S, Bhatia S. Polyamides in dentistry. Int J of Scientific Study. 2013;1(1):20-5.

[13] Hamad TI, Fatihallah AA, Abdulsahib AJ. The Effects of Different Investment Materials on Dimensional Accuracy and Surface Roughness of Thermosens Maxillary Complete Dentures. Journal of Baghdad College of Dentistry. 2015;27(3):1-7.

[14] Abdulwahhab SS. High-impact strength acrylic denture base material processed by autoclave. Journal of prosthodontic research. 2013;57(4):288-93.

[15] Hamanaka I, Takahashi Y, Shimizu H. Mechanical properties of injection-molded thermoplastic denture base resins. Acta Odontologica Scandinavica. 2011;69(2):75-9.

[16] Hamanaka I, Takahashi Y, Shimizu H. Properties of injection-molded thermoplastic polyester denture base resins. Acta Odontologica Scandinavica. 2014;72(2):13944.

[17] Al-Ameer SS. The influence of different $\mathrm{pH}$ of saliva and thermal cycling on the adaptation of different denture base materials. Scientific Journal Published by the College of Dentistry-University of Baghdad.2012; 24(3):47-53.

[18] SalahuddinN, montmorillonite

ShehataM.Polymethylmethacrylatecharacterization and properties. Polymer. 2001;42(20):8379-85.

[19] John J, Gangadhar SA, Shah I. Flexural strength of heat-polymerized polymethyl methacrylate denture resin reinforced with glass, aramid, or nylon fibers. The Journal of prosthetic dentistry. 2001;86(4):424-7.

[20] Banerjee R, Banerjee S, Prabhudesai P, Bhide S. Influence of the processing technique on the flexural fatigue strength of denture base resins: An in vitro investigation. Indian Journal of Dental Research. 2010;21(3):391.

[21] Goiato MC, Santos DMd, Haddad MF, Pesqueira AA. Effect of accelerated aging on the microhardness and color stability of flexible resins for dentures. Brazilian oral research. 2010;24(1):114-9.

[22] Takahashi Y, Hamanaka I, Shimizu H. Effect of thermal shock on mechanical properties of injection-molded thermoplastic denture base resins. Acta Odontologica Scandinavica. 2012;70(4):297-302.

[23] Yunus N, Rashid A, Azmi L, ABU-HASSAN M. Some flexural properties of a nylon denture base polymer. Journal of oral rehabilitation. 2005;32(1):65-71.

[24] Seo RS, Murata H, Hong G, Vergani CE, Hamada T. Influence of thermal and mechanical stresses on the strength of intact and relined denture bases. The Journal of prosthetic dentistry. 2006;96(1):59-67.
[25] Naranjo AO, Ibarra JG, EspinozaII AS. Influence exerted by thermal changes in the transverse deflection of acrylic materials used for denture bases, with and without metallic inserts. Revista Odontológica Mexicana. 2014;18(3):170-4.

[26] Takamata T, Setcos JC, Phillips RW, Boone ME. Adaptation of acrylic resin dentures as influenced by the activation mode of polymerization. The Journal of the American Dental Association. 1989;119(2):271-6.

[27] Miéssi AC, Goiato MC, Santos DMd, Dekon SFdC, Okida RC. Influence of storage period and effect of different brands of acrylic resin on the dimensional accuracy of the maxillary denture base. Brazilian dental journal. 2008;19(3):204-8.

[28] Parvizi A, Lindquist T, Schneider R, Williamson D, Boyer D, Dawson DV. Comparison of the Dimensional Accuracy of Injection-Molded Denture Base Materials to that of Conventional Pressure-Pack Acrylic Resin. Journal of prosthodontics. 2004;13(2):83-9.

\section{Author Profile}

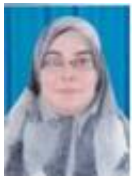

Warida A. Elnaihoum, received the B.D.S. in Dental and Oral Surgery from Benghazi University, Faculty of dentistry 2007. During 2007-2008, she practiced in Ministry of Health. Since 2009-2012, she worked as a demonstrator in BenghaziUniversity. During 2012 till now, she educated for M.S degree in prosthodontics in prosthetic department, Faculty of dentistry. Alexandria University. 